\title{
Metal-Free Catalysts for the Polymerization of Alkynyl-Based Monomers
}

\author{
Jie Zhang ${ }^{1}{ }^{\oplus}$, Zhiming Zhang ${ }^{1}{ }^{\circledR}$, Fulin Yang ${ }^{1}$, Haoke Zhang ${ }^{1}$, Jingzhi Sun ${ }^{1, *}$ and Benzhong Tang ${ }^{1,2, *}$ \\ 1 MOE Key Laboratory of Macromolecules Synthesis of Functionalization, Department of Polymer Science and \\ Engineering, Zhejiang University, Hangzhou 310027, China; zhangjieps@zju.edu.cn (J.Z.); \\ zhangzm@zju.edu.cn (Z.Z.); yangfulin@zju.edu.cn (F.Y.); zhanghk@zju.edu.cn (H.Z.) \\ 2 Department of Chemistry, Hong Kong Branch of Chinese National Engineering Research Center for Tissue \\ Restoration and Reconstruction, The Hong Kong University of Science \& Technology, Clear Water Bay, \\ Kowloon, Hong Kong, China \\ * Correspondence: sunjz@zju.edu.cn (J.S.); tangbenz@ust.edu.uk (B.T.)
}

\begin{abstract}
Novel polymerizations based on alkyne monomers are becoming a powerful tool to construct polymers with unique structures and advanced functions in the areas of polymer and material sciences, and scientists have been attracted to develop a variety of novel polymerizations in recent decades. Therein, catalytic systems play an indispensable role in the influence of polymerization efficiencies and the performances of the resultant polymers. Concerning the shortcomings of metallic catalysts, much of the recent research focus has been on metal-free polymerization systems. In this paper, metal-free catalysts are classified and the corresponding polymerizations are reviewed, including organobase-catalyzed polymerizations, Lewis-acid-catalyzed polymerizations, as well as catalyst-free polymerizations. Moreover, the challenges and perspectives in this area are also briefly discussed.
\end{abstract}

Keywords: metal-free catalysts; organobase; Lewis acid; catalyst-free; alkyne

\section{check for}

updates

Citation: Zhang, J.; Zhang, Z.; Yang, F.; Zhang, H.; Sun, J.; Tang, B. MetalFree Catalysts for the Polymerization of Alkynyl-Based Monomers. Catalysts 2021, 11, 1. https://dx.doi.org/10.3 390/catal11010001

Received: 24 November 2020 Accepted: 17 December 2020 Published: 22 December 2020

Publisher's Note: MDPI stays neutral with regard to jurisdictional claims in published maps and institutional affiliations.

Copyright: () 2020 by the authors. Licensee MDPI, Basel, Switzerland. This article is an open access article distributed under the terms and conditions of the Creative Commons Attribution (CC BY) license (https: / / creativecommons.org/ licenses/by/4.0/)

\section{Introduction}

The establishment of new polymerization techniques to easily synthesize functional polymeric materials is of vital importance to polymer and material sciences. Alkynes have been investigated as excellent monomers in recent decades. Because of their conjugated main chains, new polymers with intrinsic optoelectronic properties could be obtained [1]. With the continuous efforts of polymer scientists, many attractive alkynyl-based polymers, such as hydroxyl-yne, sulfydryl-yne, azide-alkyne, amino-yne click polymerizations, and various multicomponent or multi-group polymerizations have been established, and functional polymers have been prepared for exciting applications [2].

Catalysts can reduce the activation energy barrier and increase the reaction rate by providing an alternate pathway for a reaction to occur [3]. Metallic compounds or complexes have been widely used to catalyze alkyne-based polymerizations [4]. However, it is tedious to remove them completely from polymer products. The metallic catalysts used in the copper-mediated click polymerizations will form complexes, which are difficult to remove from the polymeric products. In a sense, the metal complexation is a crosslinking reaction, which often leads to a polymer product with a poor solubility [5]. Moreover, catalyst residues can deteriorate the photo-physical properties of the polymers; for example, their light emissions can be quenched by metallic traps. Thus, there is an urgent need to develop metal-free polymerization systems.

Compared with metallic catalysts, organobase-cataysts and Lewis-acid-catalysts have remarkable virtues, such as a good solubility in solvents, easy removal from polymers, and extremely low price. Furthermore, catalyst-free conditions might be a wiser strategy to thoroughly simplify the procedure of polymerization. Therefore, this article captures the remarkable progress in the development of the metal-free polymerization of 
alkynyl-based monomers. In this review, metal-free catalysts are classified and their corresponding polymerizations are reviewed, including organobase-catalyzed polymerizations, Lewis-acid-catalyzed polymerizations, as well as catalyst-free polymerizations, each of which has its own features and virtues. Moreover, the perspectives and challenges in this area are also briefly introduced.

\section{Organobase-Catalysts for Alkyne-Based Polymerization}

\subsection{Organobase-Catalysts for Hydroxyl-yne Polymerization}

Tri- $n$-butylphosphine $\left(n-\mathrm{Bu}_{3} \mathrm{P}\right)$ is a nucleophilic organobase-catalyst with a simple structure (Scheme 1) and cheap price. In 1995, it was used to catalyze the polyadditions of ester-activated diynes $\mathbf{1}$ and diols 2 (Scheme $2 \mathrm{~A}$ ), and the amount of $n-\mathrm{Bu}_{3} \mathrm{P}$ used in the polymerizations reached $20 \mathrm{~mol} \%$ [6-8]. Although the polymerization is less efficient, this is the first attempt at the polymerization of alkynes and alcohols.

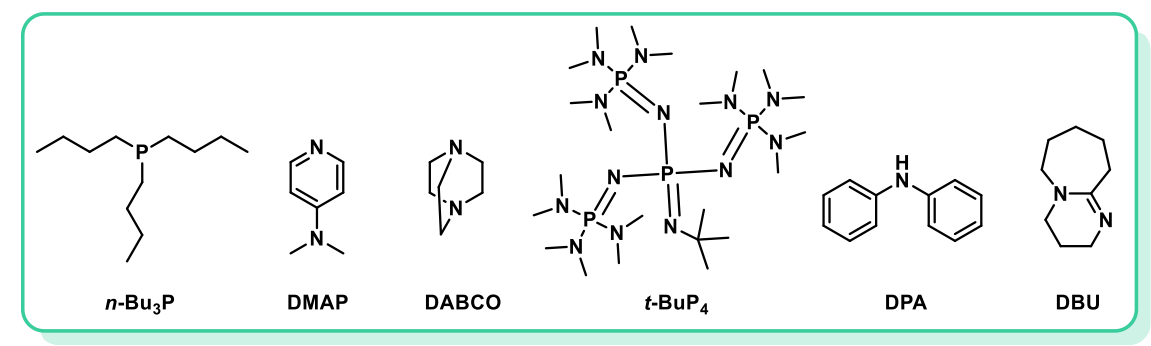

Scheme 1. Structures of organobase-catalysts used in alkyne-based polymerization.

A

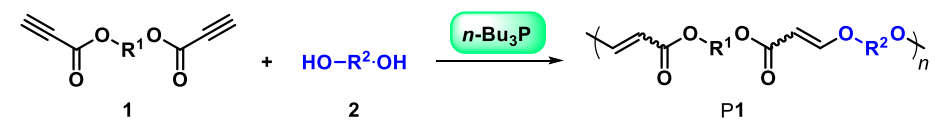

B

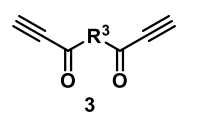

+ HO-Ar-OH

DMAP

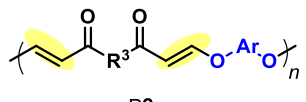

C
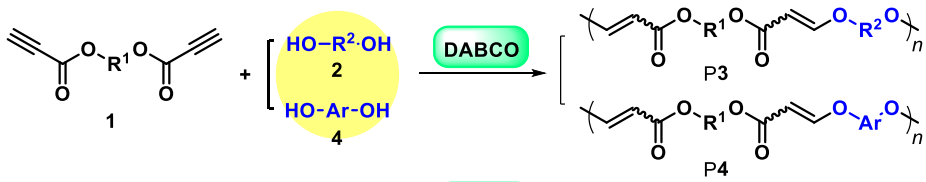

$D$
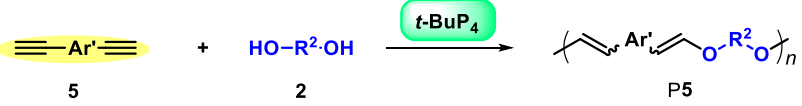

Scheme 2. Hydroxyl-yne polymerizations (A-D) with the catalysts of organobases.

With the new employment of 4-dimethylaminopyridine (DMAP), the polymerization of keto-activated diynes 3 and diphenols 4 was firstly reported in 2017 [9]. As shown in Scheme $2 \mathrm{~B}$, in the presence of DMAP the two monomers are simply mixed at room temperature, and regio-and stereoregular poly(vinylene ether ketone)s P2 can be obtained with an excellent yield after $4 \mathrm{~h}$. This DMAP-promoted polymerization has many prominent advantages - for instance, the avoidance of expensive transition-metal catalysts $[10,11]$, the mild reaction conditions, the high efficiency, and no byproducts. Furthermore, the poly (vinylene ether ketone)s are chemically stable in neutral and basic conditions but decompose rapidly when the $-\lg c(\mathrm{HCl})$ value is lower than 3.2 (Figure 1a). Thus, these poly(vinylene ether ketone)s prepared by DMAP-catalyzed phenol-yne polymerization are promising for application in biomedical and environmental fields. 

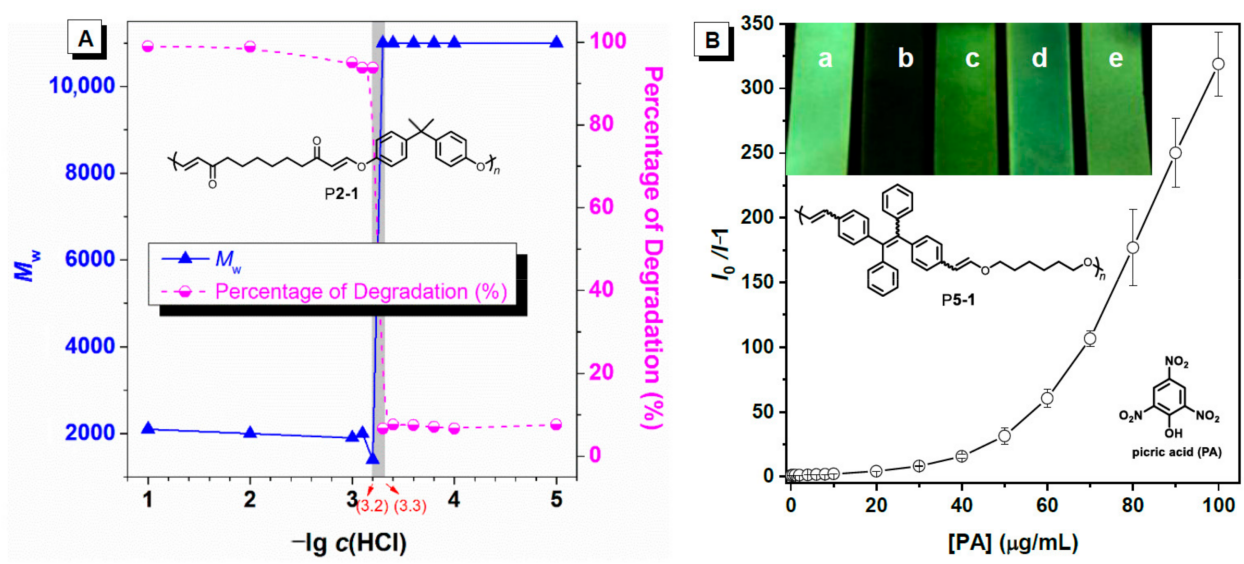

Figure 1. (A) The plots of the weight-average molecular weight $\left(M_{\mathrm{w}}\right.$, solid blue line) and percentage of degradation (dash pink line) of P2-1 versus different concentrations of hydrochloric acid. (Copyright 2017, Wiley) (B) Stern-Volmer plots of $I_{0} / I-1$ of P5-1 in tetrahydrofuran / water mixtures $\left(f_{\mathrm{w}}: 80 \%\right)$ and P5-1 in a THF versus PA concentration, where $I=$ peak intensity and $I_{0}=$ peak intensity at $[\mathrm{PA}]=0 \mu \mathrm{g} / \mathrm{mL}$. Inset: the chemical structure of PA and fluorescence images of P5-1 containing strips (, , b , c, d, and e represent strips after dipping into $0,5000,500,50$, and $5 \mu \mathrm{g} / \mathrm{mL}$ aqueous solutions of PA) upon irradiation with a hand-held lamp $(365 \mathrm{~nm})$.

$n$ - $\mathrm{Bu}_{3} \mathrm{P}$ or DMAP could only catalyze the diol-yne or phenol-yne polymerization, respectively, in the above two studies. Afterwards, researchers found that a more efficient organobase of bicyclo[2.2.2]-1,4-diazaoctane (DABCO) could catalyze both diol-yne and phenol-yne polymerizations in 2020 [12] (Scheme 2C). DABCO is a robust nucleophilic organobase-catalyst, and the polymerizations could be carried out under ambient conditions. After the systematic optimization of polymerization conditions, thermally stable poly(vinyl ether ester)s P3/P4 with high weight-average molecular weights (up to 71,000) were finally produced in excellent yields (up to $99 \%$ ) with the promotion of DABCO $(10 \mathrm{~mol} \%)$. This work established an efficient DABCO-catalyzed hydroxyl-yne click polymerization; meanwhile, it enriches the family of click polymerizations.

When the alkalinity of organic base is notably enhanced, the monomers of alkynes do not even have to be activated by ester or ketone for the hydroxyl-yne polymerization. Phosphazene bases are organic superbases, and soluble in organic solvents $[13,14]$. The uncharged organic phosphazene superbase, particularly $t$ - $\mathrm{BuP}_{4}$, has some remarkable merits, such as a highly enhanced basicity, good solubility in nonpolar solvents, hyposensitivity to oxygen and moisture, and high thermal stability [15]. Thanks to the super alkalinity of $t$ - $\mathrm{BuP}_{4}$, inactivated diynes $\mathbf{5}$ and diols $\mathbf{2}$ were successfully polymerized (Scheme 2D). A series of soluble and regio-regular anti-Markovnikov additive poly(vinyl ether)s P5 with high molecular weights $\left(M_{\mathrm{w}}\right.$ up to 40,600$)$ were obtained in high yields (up to $99 \%$ ) [16]. The tetraphenylethene (TPE)-containing P5-1 showed characteristics of aggregation-enhanced emission (AEE), and its aggregates exhibited a super-amplification quenching effect to picric acid, which could be potentially used in explosive detection (Figure 1b). Similar to poly(vinylene ether ketone)s, the poly(vinyl ether)s are degradable under acidic conditions, and thus may be used in the field of drug release.

Only two works of metal-catalyzed hydroxyl-yne polymerizations were reported in $2019[17,18]$. The catalysts used in the two works are $\mathrm{Pd}\left(\mathrm{PPh}_{3}\right)_{4}$ and $\mathrm{Cs}_{2} \mathrm{CO}_{3}$. Compared with noble metal complexes, organobase catalysts are more available at very low prices. Compared with inorganic salts, organobases can completely dissolve in solvents, forming a homogeneous catalytic system. Therefore, organobase-catalyzed hydroxyl-yne polymerizations have been well developed in recent years. 


\subsection{Organobase-Catalysts for Sulfydryl-yne Polymerization}

Organic bases could also catalyze thiol-yne polymerization. In 1995, the Endo group [19-21] firstly reported the organocatalyzed polymerization of alkynes and thiols. Simply mixing the ester-activated diynes 6 and dithiols 7 in the presence of $n-\mathrm{Bu}_{3} \mathrm{P}$ at ambient conditions readily produced P6 with a high molecular weight $\left(M_{n}=20,700\right)$ after $1 \mathrm{~h}$ (Scheme 3A). This polymerization catalyzed by an organic base has the favorable characteristics of simplicity, efficiency, and conditional mildness, promising a powerful polyaddition reaction.

A

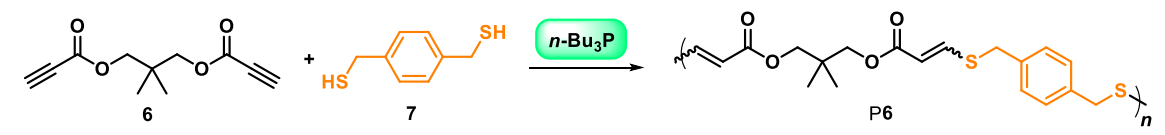

$B$

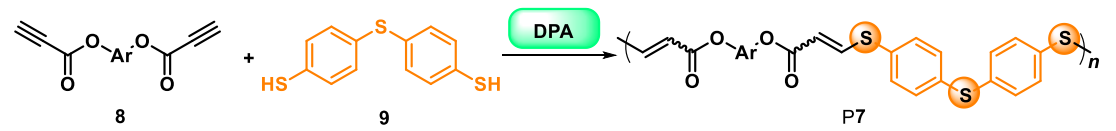

C

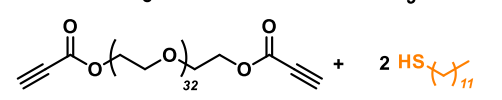

10

11
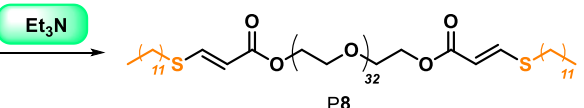

D

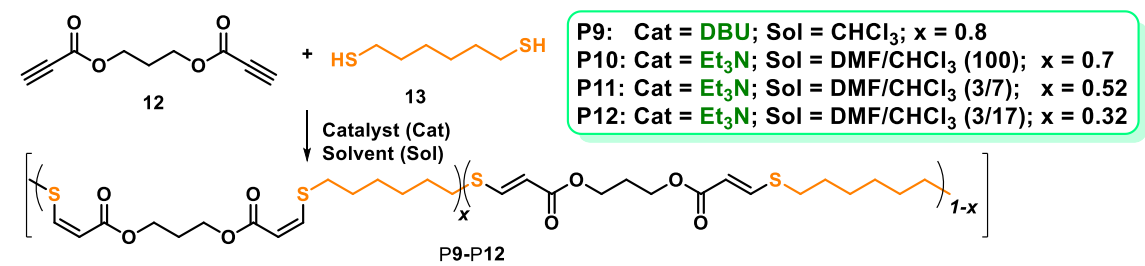

Scheme 3. Sulfydryl-yne polymerizations (A-D) with the catalysts of organobases.

When the dithiols were replaced with diphenols, the organocatalyzed sulfydryl-yne polymerizations could also be established. In the presence of diphenylamine (DPA), the alkyne polyhydrothiolations of ester-activated diyne 8 and dithiophenol 9 proceed smoothly at room temperature, furnishing the sole anti-Markovnikov products of poly (vinylenesulfide)s P7 (Scheme 3B) with high molecular weights $\left(M_{\mathrm{w}}\right.$ up to 32,300) and high stereoregularities ( $Z$ content up to $81.4 \%$ ) in high yields (up to 98.2\%) [22]. The poly(vinylene sulfide)s are optically transparent, allowing almost all visible and IR light to transmit through, and their films show high refractive indices $(\mathrm{n}=1.73-1.70)$ and low optical dispersions ( $\mathrm{D}^{\prime}$ down to 0.002 ) in the wavelength region of $500-1700 \mathrm{~nm}$. With the promotion of DPA, a new synthetic route for sulfur-rich polymers has been developed.

Soon afterwards, Dove group realized a polymer-polymer coupling though an organocatalytic click addition of thiol 12 to ester-activated alkyne 10 (Scheme 3C) [23]. Compared with primary amine and secondary amine, the author found that $\mathrm{Et}_{3} \mathrm{~N}$ is the best catalyst. Most of the selected amine catalysts have very similar $\mathrm{p} K_{\mathrm{a}}$ values, so the basicity of the catalysts is probably not the main thing that affects their reaction activity in these reactions. Although the basicity of tertiary amine diisopropylethylamine (DIPEA, $\mathrm{p} K_{\mathrm{a}}=11.4$ ) is higher than that of $\mathrm{Et}_{3} \mathrm{~N}\left(\mathrm{pK} K_{\mathrm{a}}=10.7\right)$, it does not show any catalysis, which indicates that steric hindrance is the main factor of catalyst activity in the polymer-polymer coupling reaction.

Based on the above research, the same group reported another organocatalyzed polymerization of ester-activated alkynes and thiols in 2016 [24]. In this work, ester- activated alkyne 12 was combined with hexane dithiol 13 in chloroform $\left(\mathrm{CHCl}_{3}\right)$ in the presence of $1 \mathrm{~mol} \%$ of 1,8-diazabicycloundecane (DBU) to promote the polymerization (Scheme 3D). After only $1 \mathrm{~h}$, P9 with a high cis-content (80\%) was obtained. Interestingly, changing the polarity of the reaction solvent could result in polymers with different cis/trans ratios (P9-P12). The resulting controllable double-bond stereochemistry defines the crystallinity and the concomitant mechanical properties as well as enabling the synthesis of materials that retain their excellent mechanical properties through changing monomer compositions. Thus, the organocatalytic control of stereochemistry opened the realm to a new and easily 
scalable class of elastomers that will have unique chemical handles for functionalization and post synthetic processing.

\subsection{Organobase-Catalysts for Alkyne-Azide Polymerization}

Alkyne-azide polymerization is well known as the most famous click polymerization. Organobase-catalysts play an indispensable role in the development of alkyne-azide polymerization.

Recently, two interesting studies were reported in succession and showed that two different organobase-catalysts could catalyze the same polymerization $[25,26]$. As clearly shown in Scheme 4, the same monomers of diynes $\mathbf{5 a}$ and $\mathbf{5 b}$ and diazides $\mathbf{1 4}$ were polymerized by the catalysis of $\mathrm{NMe}_{4} \mathrm{OH}$ or $t-\mathrm{BuP}_{4}$, producing polytriazoles of P13a-N, P13b-N, P13a-P, and P13a-P. Although the polymers were all 1,5-regioisomers, the other performances of the polymerization catalyzed by $\mathrm{NMe}_{4} \mathrm{OH}$ or $t$ - $\mathrm{BuP}_{4}$ were totally different. The results are summarized in Table 1 . Compared with the yields of $\mathrm{NMe}_{4} \mathrm{OH}-$ catalyzed polymerizations, the yields of $t$-BuP 4 -catalyzed ones are much higher. However, the $\mathrm{NMe}_{4} \mathrm{OH}$-catalyzed ones excel in another evaluation index, such as $M_{\mathrm{W}}$, structural regularity, and conditional mildness.

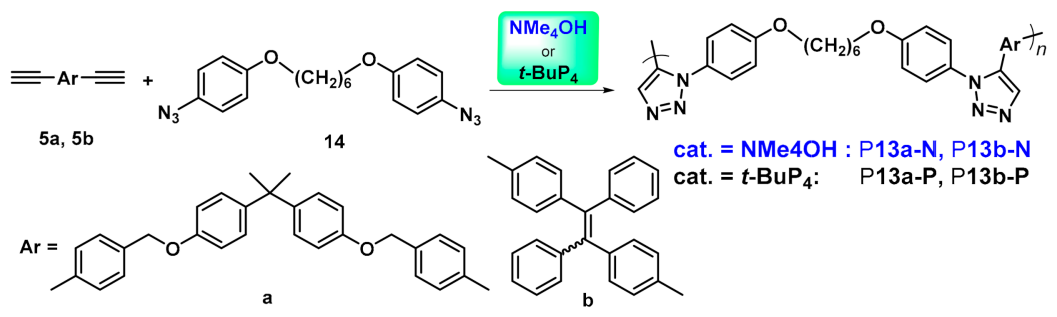

Scheme 4. alkyne-azide polymerizations catalyzed by $\mathrm{NMe}_{4} \mathrm{OH}$ or $t-\mathrm{BuP}_{4}$.

Table 1. Different performances of polymerizations with different organobase-catalysts.

\begin{tabular}{ccccccccc}
\hline Catalysts & Polymers & Monomers & $\mathbf{T}\left({ }^{\circ} \mathbf{C}\right)$ & [cat.]/[14] & $\boldsymbol{M}_{\mathbf{w}}$ & PDI & $\begin{array}{c}\text { Yield } \\
\mathbf{( \% )}\end{array}$ & $\begin{array}{c}\boldsymbol{F}_{\mathbf{1 , 5}} \mathbf{c}^{\mathbf{c}} \\
\mathbf{( \% )}\end{array}$ \\
\hline $\mathrm{NMe}_{4} \mathrm{OH}$ & P10a-N & $\mathbf{9 a}+\mathbf{1 0}$ & 25 & 1 & $44,000^{\mathrm{a}}$ & 1.41 & 86 & 92 \\
$t-\mathrm{BuP}_{4}$ & $\mathrm{P} \mathbf{1 0 a}-\mathbf{P}$ & $\mathbf{9 a}+\mathbf{1 0}$ & 80 & 0.5 & $9600^{\mathrm{b}}$ & 1.44 & 97 & 87 \\
$\mathrm{NMe}_{4} \mathrm{OH}$ & $\mathbf{P 1 0 b}-\mathbf{N}$ & $\mathbf{9 b}+\mathbf{1 0}$ & 25 & 1 & $40,300^{\mathrm{a}}$ & 1.45 & 85 & 100 \\
$t-\mathrm{BuP}_{4}$ & P10a-P & $\mathbf{9 b}+\mathbf{1 0}$ & 80 & 0.5 & $12,000^{\mathrm{b}}$ & 1.43 & 99 & 100 \\
\hline
\end{tabular}

a Estimated by gel permeation chromatography (GPC) in dimethyl formamide containing $0.05 \mathrm{M} \mathrm{LiBr}$ on the basis of a polystyrene calibration; $M_{\mathrm{W}}=$ weight-average molecular weight; PDI $=M_{\mathrm{W}} / M_{\mathrm{n}}$.

b Estimated by GPC using tetrahydrofuran as an eluant on the basis of polystyrene calibration.

${ }^{c}$ Fraction of the 1,5-regioisomer determined by ${ }^{1} \mathrm{H}$ NMR.

\section{Acid-Catalysts for Alkyne-Based Polymerization}

Multicomponent polymerization (MCP) as a powerful and popular synthetic approach for functional polymers with a great structural diversity has been demonstrated to be a promising tool for the construction of novel materials. MCP enjoys a series of advantages, such as great structural diversity, various monomer combination strategies, high efficiency and convenience, mild conditions, and environmental benefits [27]. Lewis-acid often plays a crucial role in the catalyst system for MCP.

In 2017, the $\mathrm{Hu}$ group developed a facile $\mathrm{AcOH}$-catalyzed MCP of activated internal alkyne 16, aromatic diamines 15/17, and formaldehyde 18 to synthesize structural-regulated and sequence-controlled polyheterocycles with high molecular weights (up to 69800 ) in high yields (up to 99\%) [28]. Noticeably, if the combination and feeding sequence of two diamine monomers 15/17 were changed, the four-component polymerization could afford sequence-controlled polymers P14-P17 (Scheme 5A). Through such MCP, polymers with in situ-generated multi-substituted tetrahydropyrimidines or dihydropyrrolones in the 
backbone and inherent luminescence can be easily obtained with a high atom economy and environmental benefit, which is inaccessible by other synthetic approaches.

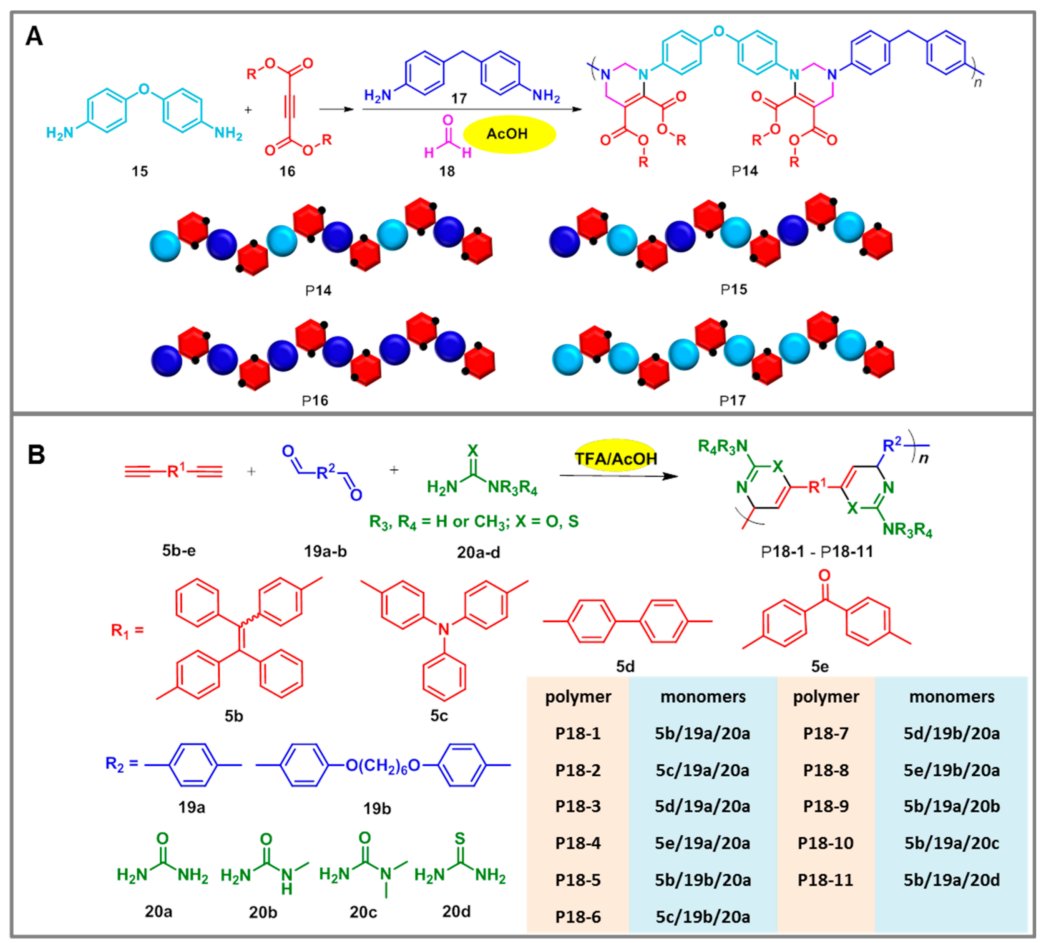

Scheme 5. Two kinds of multicomponent polymerizations (A), (B) with acid-catalysts.

Based on the same methodology and the same $\mathrm{AcOH}$-catalyzed system, four hyperbranched polymers with various topological structures as well as sequences of different functional groups in the polymer backbone were obtained (molecular weights up to 30,000 and yield up to $98 \%$ ) [29]. The hyperbranched polymers were designed to be aggregationinduced emission (AIE)-active, which mean they emitted luminescence faintly in solution, while the luminescence was notably enhanced in the aggregated state. It is anticipated that the MCP may provide a synthetic platform for the construction of hyperbranched polyheterocycles with diverse structures and functionalities.

Another kind of acid-catalyzed MCP was reported in 2019 [30]. With a combined promotion of TFA / AcOH, a series of multifunctional polyheterocycles with AIE characteristics were generated by the MCPs of terminal diynes $\mathbf{5 b}-\mathbf{e}$, dialdehydes $19 a$ and $\mathbf{1 6 b}$, and ureas 20a-d. Most of the polymers were synthesized with high molecular weights $\left(M_{\mathrm{W}}\right.$ up to 49,900 ) in nearly quantitative yields and displayed intense solid-state emission and a remarkable fluorescence response to protonation and deprotonation. Thus, a sensitive and reversible fluorescent sensor for ammonia was developed to detect biogenic amines and seafood spoilage (Figure 2a,b). Besides this, the polymer-based nanoparticles showed excellent lysosome-targeting specificity in cell imaging (Figure 2c-j). These polyheterocycles have a specific $\mathrm{pH}$-sensitive behavior and can respond in the wide range of $\mathrm{pH} 1-9$, and thereby can be used for the physiological $\mathrm{pH}$ visualization of the gastrointestinal tract. The in vivo mapping of the freshwater Cladocera Moina macrocopa intestinal $\mathrm{pH}$ tract showed an increased $\mathrm{pH}$ gradient from approximately 4.2 to 7.8 along the foregut, midgut, and hindgut. Therefore, the polymers obtained through the acid-catalyzed MCPs show great potential in biological applications both in vitro and in vivo. 


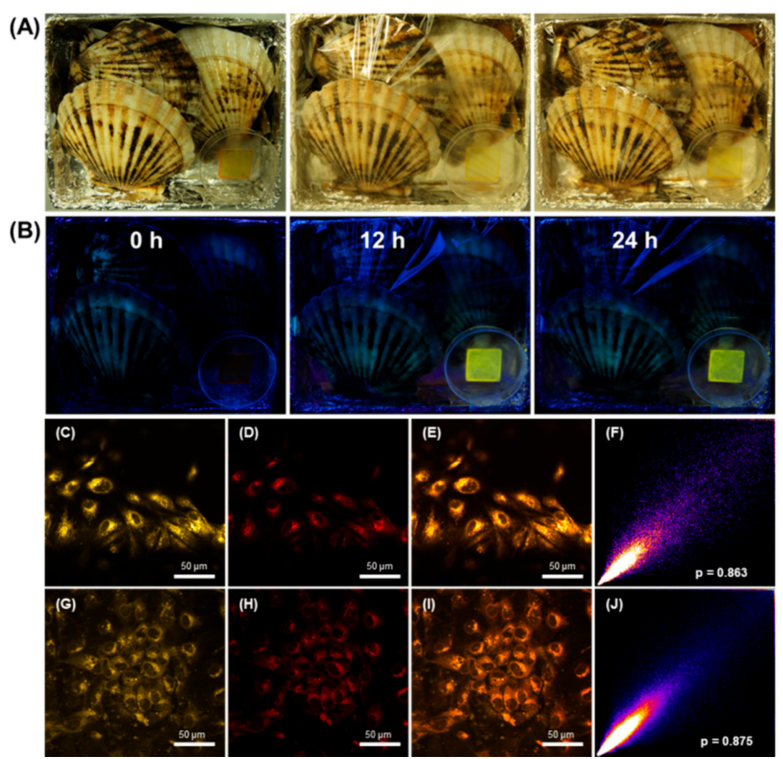

Figure 2. (A,B) Spoilage detection of scallops in sealed packages for $24 \mathrm{~h}$ at room temperature using H2P15a/16a/17a2+ thin film. Photographs taken under (A) normal room light. (B) $365 \mathrm{~nm} \mathrm{UV}$ irradiation. (C-J) Confocal images of ZF4 cells co-stained by (C-F) P18-1 $\left(10 \times 10^{-6} \mathrm{~m}, 2 \mathrm{~h}\right)$ or $(\mathrm{G}-\mathbf{J})$ P18-6 $\left(10 \times 10^{-6} \mathrm{~m}, 2 \mathrm{~h}\right)$ with LysoTracker Red (LTR, $\left.10 \times 10^{-6} \mathrm{~m}, 0.5 \mathrm{~h}\right)$. (C,G) Yellow channel: excitation wavelength at $405 \mathrm{~nm}$ and emission range at 500-600 nm for P18-1 and P18-6. (D,H) Red channel: excitation at $561 \mathrm{~nm}$ and emission range in 580-680 nm for LTR. (E,I) Merged image of yellow and red channel. $(\mathbf{F}, \mathbf{J})$ Scatter plot indicated the overlap coefficient between the imaging result of P18-1 or P18-6 with LTR (inset: Pearson's correlation coefficient). (Copyright 2019, Wiley).

Further, three-group polymerizations have been realized with Lewis-acid-catalysts by the ingenious design of monomers, such as alkyne-aldehyde monomer $\mathbf{2 1}$ and alkyne-nitrile monomer 23.

Under the catalysis of $\mathrm{B}\left(\mathrm{C}_{6} \mathrm{~F}_{5}\right)_{3}$ [31], a novel synthetic route to polyquinolines P19 with 6-substituted quinoline as the structural unit was developed based on the polymerization of alkyne-aldehyde monomer 21 and aniline derivative 22 (Scheme 6A). The polymerization was conducted in dichloroethane at $100^{\circ} \mathrm{C}$ for $36 \mathrm{~h}$ under air atmosphere, affording polyquinolines P19 with molecular weights of up to 13,100 and a good solubility in most organic solvents.

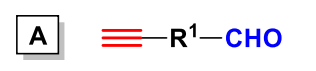

21

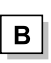

23

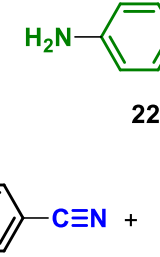

22

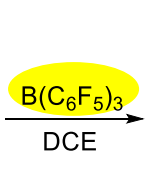

PhIO

24

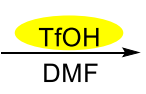

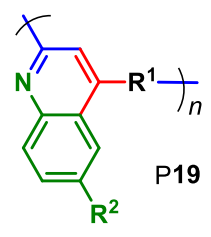

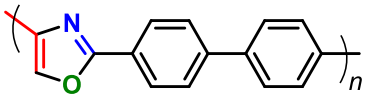

P20

Scheme 6. Three-group polymerizations (A,B) with Lewis-acid-catalysts.

Similarly, a three-group [2+2+1] cycloaddition polymerization of alkyne-nitrile monomer 23, and O-atom for the regioselective assembly of highly substituted oxazole compounds has been achieved by the use of iodosobenzene (PhIO) 24 with the catalysis of trifluoromethanesulfonic acid (TfOH) [32], which is clearly shown in Scheme 6B. Polyoxazole with a satisfactory solubility, thermal stability, and relative molecular weight was obtained by optimizing the polymerization conditions. Moreover, the polyoxazoles with unreacted 
terminal alkynes and nitriles showed a good thermal stability, and thus have potential applications in modified resin.

Lewis acid could not only promote some of MCPs, but also perform as one component of monomers. In 2016, Tang's group [33] presented a $\mathrm{BCl}_{3}$-mediated $\mathrm{MCP}$ route for the construction of stereoregular functional polymers (Scheme 7A). The MCP of terminal diyne 5 , monoaldehyde 25 , and $\mathrm{BCl}_{3}$ that proceeds at $0{ }^{\circ} \mathrm{C}$ for $1 \mathrm{~h}$ followed by stirring at room temperature for another $3 \mathrm{~h}$ afforded poly(dichloropentadiene)s with a predominant $(E, Z)$ configuration in high yields (up to $92 \%$ ) with high molecular weights $\left(M_{\mathrm{w}}\right.$ up to 174,300$)$.
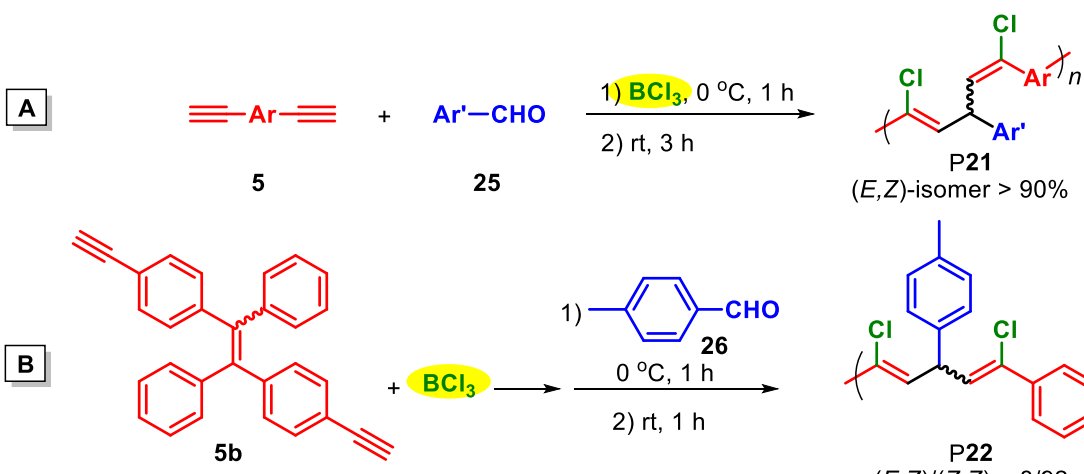

$(E, Z)$-isomer $>90 \%$
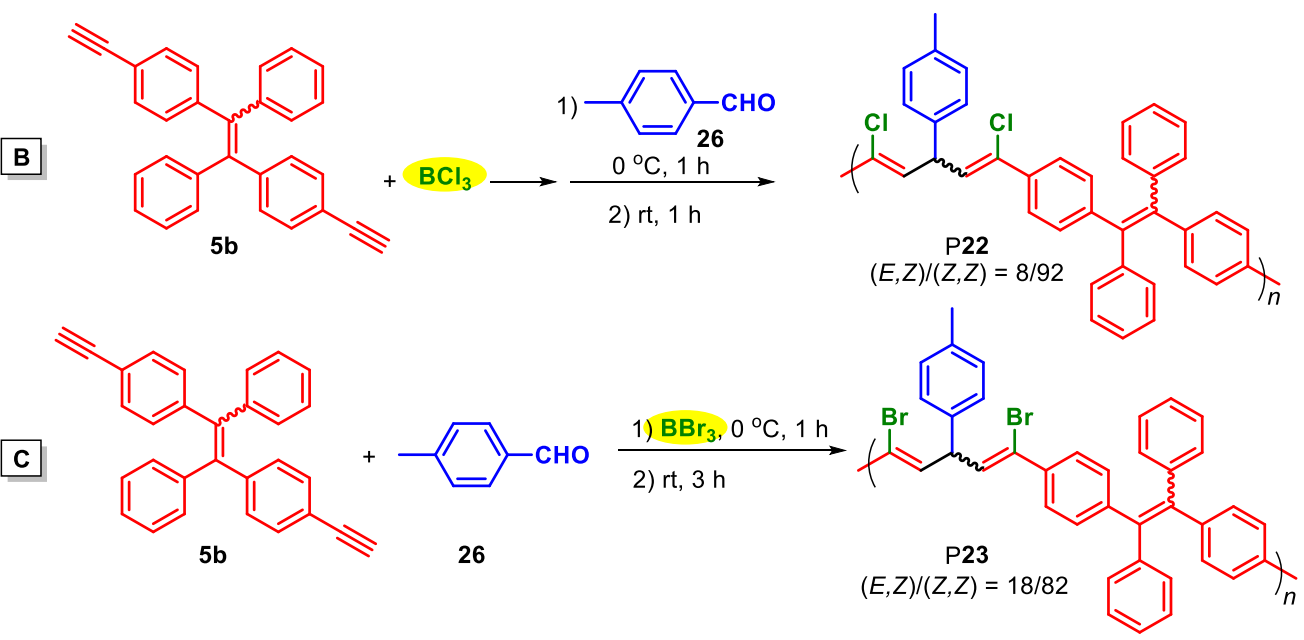

Scheme 7. Three-component polymerizations (A-C) with $\mathrm{BCl}_{3} / \mathrm{BBr}_{3}$ catalysts.

Significantly, totally different configurations of poly(dichloropentadiene)s with 1,5dihalo-(Z,Z)-1,4-pentadiene as dominated segments were achieved two years later [34]. When diyne 15a and $\mathrm{BCl}_{3}$ were allowed to react at $45^{\circ} \mathrm{C}$ for $1 \mathrm{~h}$ prior to further coupling with aldehyde at $0{ }^{\circ} \mathrm{C}$ and room temperature, a high molecular weight polymer (P22, $\left.M_{\mathrm{w}}=119,700\right)$ with a mainly $(Z, Z)$-configuration was obtained in a satisfactory yield. The content of the $(Z, Z)$-isomeric unit of P22 was determined to be up to $92 \%$. While the mediator of Scheme 7A was replaced from $\mathrm{BCl}_{3}$ to $\mathrm{BBr}_{3}$ (Scheme $7 \mathrm{C}$ ), it also resulted in polymers with a predominant $(Z, Z)-1,4$-pentadiene unit (P23) in a good yield of 79\% with a high $M_{\mathrm{w}}$ of 63,100 . Therefore, the stereoselectivity of the polymerization was demonstrated to be highly dependent on the reaction conditions as well as employed boron trihalide species.

\section{Catalyst-Free Polymerization}

Compared with organobase-catalysts or Lewis-acid-catalysts, catalyst-free conditions might be a wiser strategy for the polymerization of alkynyl-based monomers, which extremely simplify the procedure of polymerizations. Here, photo-/thermoinitiated or even spontaneous polymerizations will be introduced below.

\subsection{Catalyst-Free Azide-Alkyne Polymerization}

As the most classical and earliest click polymerization, azide-alkyne polymerization has been soundly developed, and the exploration of catalyst-free azide-alkyne polymerizations has taken a great proportion. Many endeavors have been paid to the development of catalyst-free azide-aklyne polymerizations, some comprehensive reviews on this method- 
ology have been published in recent years $[4,35,36]$. Synoptically, four reforms are of vital importance.

First, keto-activated alkynes were used to polymerize with azides to produce linear or hyperbranched 1,4-regioregular PTAs under heating (Scheme 8A). This polymerization shows wonderful advantages, such as moderate reaction conditions, high efficiency, and regioselectivity. Afterwards, this strategy has been used to synthesize plentiful polytriazoles with various structures and diversiform properties like optical nonlinearity, adjustable light refractivity, self-healing, aggregation-induced emission (AIE), and photonic patterning $[5,37,38]$. Second, ester-activated alkynes were employed to the catalyst-free azide-alkyne polymerizations (Scheme 8B), successfully avoiding the tedious procedures and harsh reaction conditions of the synthesis of keto-activated alkynes [39-45]. Third, activated azides were involved in the catalyst-free azide-alkyne polymerization (Scheme 8C) [46-49], which was inspired by the strategy of activating alkynes.

A
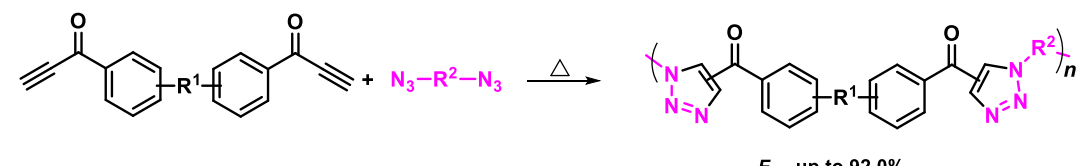

B

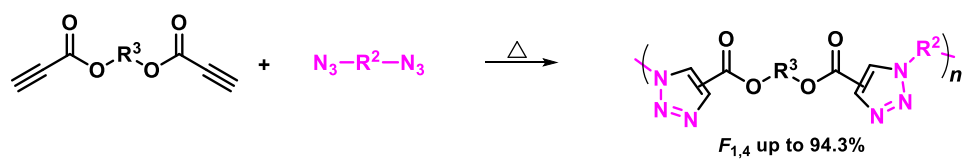

C
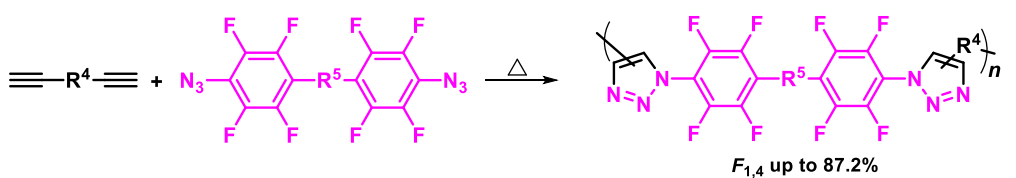

D

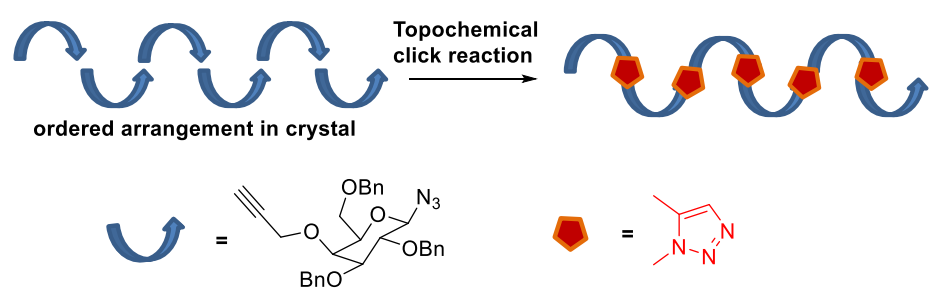

Scheme 8. Four reforms (A-D) for the catalyst-free azide-alkyne polymerizations.

In the last, the proximity was taken as the driving force for the catalyst-free azidealkyne polymerization (Scheme 8D) [50-54]. Because ethynyl and azide groups, the reaction units, are wrapped in the lattice, the structure is similar to their transition-state-like arrangement, which promotes cycloaddition in catalyst-free and solvent-free conditions.

\subsection{Catalyst-Free Thiol-yne Polymerization}

Besides the extensive reports on catalyst-free polymerizations of alkyne and azide, the research on catalyst-free thiol-yne polymerization has found growing interest in the last decade.

Since the pioneering work of Perrier in 2009 [55], the photo-/thermoinitiated thiolyne click polymerization of $\mathrm{AB}_{2}$-type monomers 27 has been systematically investigated (Scheme 7A). It is widely applied in the preparation of functional hyperbranched polymers with such versatile properties as self-assembly, drug-release, biodegradability, thermoresponse, photoluminescence, and liquid crystallinity [56-62]. Linear polymers P25 can also be prepared via the photo-/thermoinitiated thiol-yne polymerization of monoyne 28 and dithiol monomers 29 (Scheme 9B) [63]. Moreover, Voit et al. [64,65] found that by controlling the ratio of mercapto and ethynyl groups (Scheme 9C), poly(vinyl sulfide)s P26 was able to be prepared based on the selective and quantitative mono-addition reaction between sulfhydryl 29 and ethynyl 30. This novel thiol-yne polymerization method can 
also be used in the fields of organic light-emitting diodes and planar one-dimensional all-polymer photonic crystals. The synthesized hyperbranched poly(vinyl sulfide)s have unique properties such as processability, thermal stability, high transparency, high reflective indices, and low optical dispersion [66-68]. All these photo-/thermoinitiated thiol-yne polymerizations proceed via a free-radical mechanism.

A

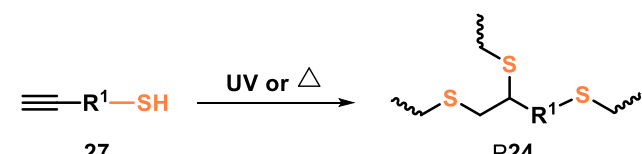

$B$

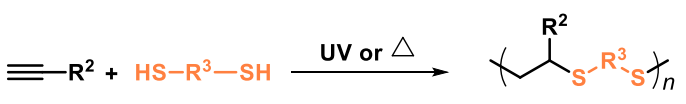

28

29

P25

C

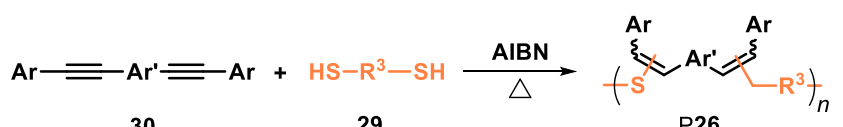

30

29

P26

Scheme 9. Photo-/thermoinitiated thiol-yne polymerzations (A-C).

UV light or elevated temperature is needed for the aforementioned thiol-yne polymerizations, which greatly complicates the experimental operation and limits its application. In 2014, a facile and powerful thiol-yne click polymerization was developed, which could be carried out under very mild conditions without any catalyst or assistant [69]. Simply mixing the aromatic diynes $\mathbf{5 f}$ and dithiols 30 with an equivalent molar ratio in THF at $30^{\circ} \mathrm{C}$ could readily produce regioregular functional poly(vinylene sulfide)s P27 with high molecular weights ( $M_{\mathrm{w}}$ up to 85,200) in excellent yields (up to 97\%) within $2 \mathrm{~h}$ (Scheme 10A). Furthermore, no double addition product of an ethynyl group was found. This spontaneous thiol-yne click polymerization has remarkably simplified the reaction conditions and will facilitate the preparation of functional materials applied in diverse areas. One year later, the same authors prepared multifunctional hyperbranched poly(vinylene sulfide)s by the spontaneous thiol-yne click polymerization for the first time [70]. When replacing 5f with 1,4-diethynyl triptycene, triptycene-containing poly(vinylene sulfone) derivatives were well prepared based this kind of spontaneous thiol-yne click polymerization in 2018 [71].

A

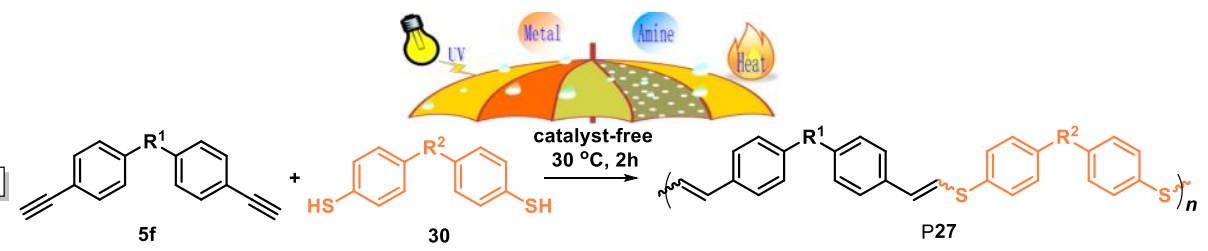

B

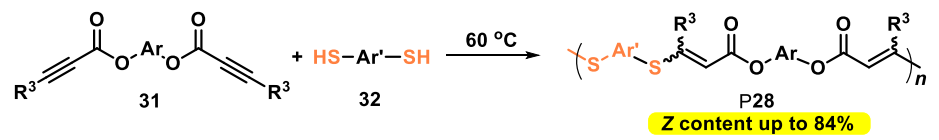

Scheme 10. Catalyst-free thiol-yne polymerzations (A,B). (Copyright 2014, ACS).

In 2020, terminal alkynes were further replaced with ester-activated internal alkynes to improve the stereoregularity of polymers produced in thiol-yne polymerizations [72]. As shown in Scheme 10B, the polymerizations of ester-activated internal diyne $\mathbf{3 1}$ and dithiol 32 performed in $\mathrm{N}, \mathrm{N}$-dimethylformamide (DMF) at $60{ }^{\circ} \mathrm{C}$ in an open atmosphere, producing poly( $\beta$-thioacrylate)s P28 with high stereoregularities ( $Z$ content up to $84 \%$ ).

\subsection{Spontaneous Amino-yne Polymerization}

Great progress was made in 2017. He B. et al. successfully realized catalyst-free aminoyne click polymerizations for the first time [73], which opened the door to catalyst-free 
amino-yne click polymerizations. Without the assistance of catalyst or external stimuli, the polymerization of ester-activated diynes $\mathbf{1}$ and diamines $\mathbf{3 4}$ carried out smoothly at room temperature, and 100\% E-poly( $\beta$-aminoacrylate)s P29 with high molecular weights $\left(M_{\mathrm{W}}\right.$ up to 64,400$)$ were readily generated in excellent yields (Scheme 11A). By incorporating the TPE moiety in the main chains, this spontaneous amino-yne polymerization could be applied to prepare AIE-active polymers, becoming a powerful tool in explosive detection and bioimaging. Compared with $\mathrm{CuCl}$-catalyzed amino-yne click polymerization at $140{ }^{\circ} \mathrm{C}$, which was set up by the same author in 2016 [74], the spontaneous reaction system at room temperature possesses incomparable advantages. In 2020 [75], the same authors also succeeded in developing a multicomponent tandem polymerization to transform ester-activated internal diynes 35 and diamines 34 into poly(aminomaleimide)s P32 (Scheme 11D) with unique nontraditional intrinsic luminescent properties without any catalyst.

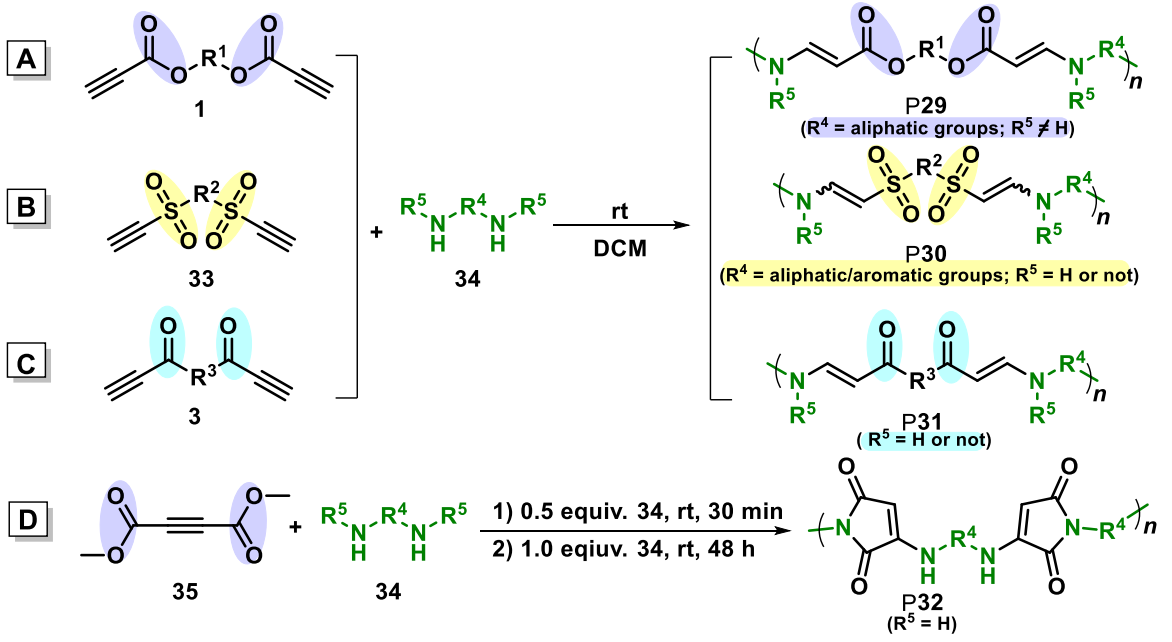

Scheme 11. Spontaneous amino-yne polymerizations (A-D).

Then, a new kind of activated diynes of bis-(ethynylsulfone)s 33, in which the ethynyl groups are activated by the sulfonyl groups, was rationally designed [76]. By using the activated diynes, a novel synthetic route of spontaneous amino-yne click polymerization was successfully opened (Scheme 11B). Compared with the ester-activated diynes, sulfonyl-activated diynes could polymerize with all kinds of diamines including aliphatic and aromatic primary and secondary ones, and poly( $\beta$-aminovinylsulfone)s P30 with high molecular weights $\left(M_{\mathrm{W}}\right.$ up to 160,000$)$ and excellent regio- and stereoregularity (the ratio of $E$ isomers up to $100 \%$ ) were obtained in good yields. Due to the strong electronwithdrawing ability of sulfonyl groups, P30 can exchange amines and easily degrade after the addition of monoamines. In a word, a novel spontaneous amino-yne click polymerization with regio- and stereoregular rules emerged. The synthesized polymer is dynamically degradable and can be used to label bioconjugates.

Afterwards, it was reported that keto-activated diynes 3 could be employed in the amino-yne polymerization under ambient conditions without the addition of any catalysts (Scheme 11C) [77]. Poly( $\beta$-enaminone)s P31 could be produced in an excellent yield (up to $99 \%$ ). More importantly, the polymerization of keto-activated diynes with different types of amines showed different stereoselectivities. When secondary amines were used, polymers with a sole E-configuration were obtained, whereas $100 \%$ Z-configuration polymers were constructed using primary amines. By employing DFT calculation, the extraordinary stereoselectivity of such reactions was well explained. Taking advantage of the dynamic bonds in P31, the degradation reaction of polymers generated by the click polymerization of secondary diamines and bis(aroylacetylene)s was systematically investigated, which could produce definite degradation products. Thus, this work provides an efficient amino-yne click polymerization for synthesizing degradable nitrogen-containing polymers. 
The most remarkable example of spontaneous amino-yne polymerization occurred in living cells [78]. A lab-in-cell is illustrated in Figure 3. Keto-activated diyne 3-1 can spontaneously polymerize with TPE-containing primary diamine 34-1 inside cells, and polymer P33 with weight-average molecular weight of 7300 was yielded. By utilizing this in vivo amino-yne polymerization and taking advantage of the AIE feature of TPE, a "turn-on" cell imaging was realized, and the in situ killing of cells was also acquired by destroying the structures of actin and tubulin, which cannot be realized by a pre-prepared polymer. This strategy provided a useful platform and hold great promise in biochemistry and therapy applications.

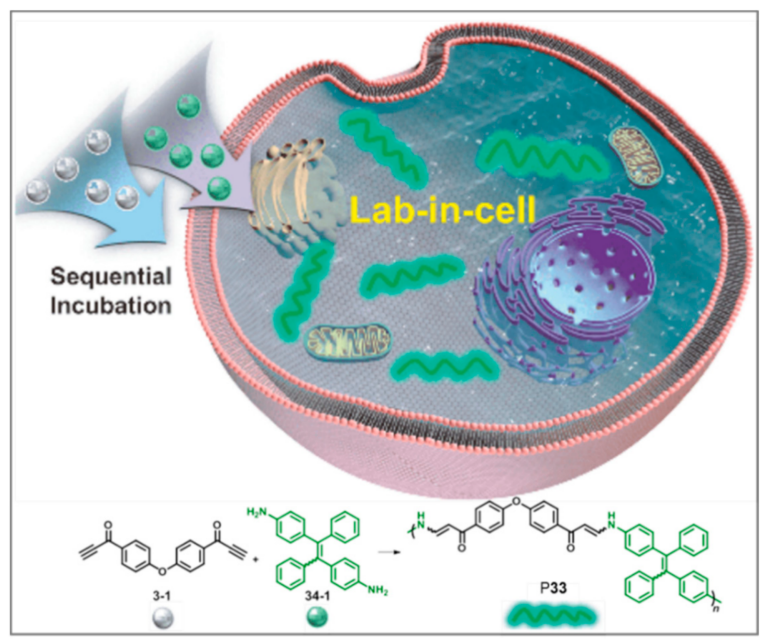

Figure 3. Illustration of the spontaneous amino-yne polymerization in cell. (Copyright 2019, Springer).

\section{Conclusions and Perspective}

From the viewpoint of catalytic systems, the progress on metal-free polymerizations of alkynyl-based monomers has been classified and introduced. In conclusion, organic bases are frequently employed to catalyze click polymerizations, such as hydroxyl-yne, sulfydrylyne, and azide-alkyne ones, while Lewis-acids are usually used in the catalysis of multicomponent polymerizations or multi-group polymerizations. Catalyst-free polymerizations are normally photo-/thermo-initiated or even proceed spontaneously. All these kinds of metal-free polymerizations of alkynyl-based monomers enjoy incomparable advantages without the problem of catalyst-residual. Thus, these well-developed polymerization methodologies and corresponding polymers are very suitable for the requirements of biology and optoelectronics.

Up to now, almost all of the catalyst-free polymerizations of alkynyl-based monomers belong to various categories of click polymerizations. The family of photo-/thermoinitiated/spontaneous multicomponent polymerizations of alkynyl-based monomers is yet to be exploited and expanded. Although there was one report entitled "Catalyst-Free, Atom-Economic, Multicomponent Polymerizations of Aromatic Diynes, Elemental Sulfur, and Aliphatic Diamines toward Luminescent Polythioamides" in 2015 [79], the prospects in this aspect are broad. Meanwhile, the applications of these metal-free polymerizations keep up with the pace of polymeric methodologies, and more brilliant works will come into the view in the scientific world. We believe that this feature article will attract more and more talented practitioners to embrace these challenges of vast potential. 
Author Contributions: J.Z. researched and wrote the original draft; Z.Z. and F.Y. polished the original draft. H.Z. and B.T. revised the original draft. J.S. organized and revised the original draft preparation. All authors have read and agreed to the published version of the manuscript.

Funding: This research was funded by National Natural Science Foundation of China: 22021715, 21490571. Institutional Review Board Statement: Not applicable.

Informed Consent Statement: Not applicable.

Data Availability Statement: Please refer to suggested Data Availability Statements in section “MDPI Research Data Policies" at https://www.mdpi.com/ethics.

Conflicts of Interest: The authors declare no conflict of interest.

\section{References}

1. Wang, X.; Sun, J.Z.; Tang, B.Z. Poly(disubstituted acetylene)s: Advances in polymer preparation and materials application. Prog. Polym. Sci. 2018, 79, 98-120. [CrossRef]

2. Wang, K.; Amin, K.; An, Z.; Cai, Z.; Chen, H.; Chen, H.; Dong, Y.; Feng, X.; Fu, W.; Gu, J.; et al. Advanced functional polymer materials. Mater. Chem. Front. 2020, 4, 1803-1915. [CrossRef]

3. Djéga-Mariadassou, G.; Boudart, M. Classical kinetics of catalytic reactions. J. Catal. 2003, 216, 89-97. [CrossRef]

4. Qin, A.; Lam, J.W.Y.; Tang, B.Z. Click polymerization. Chem. Soc. Rev. 2010, 39, 2522-2544. [CrossRef]

5. Qin, A.; Jim, C.K.W.; Lu, W.; Lam, J.W.Y.; Häussler, M.; Dong, Y.; Sung, H.H.Y.; Williams, I.D.; Wong, G.K.L.; Tang, B.Z. Click polymerization: Facile synthesis of functional poly(aroyltriazole)s by metal-free, regioselective 1,3-dipolar polycycloaddition. Macromolecules 2007, 40, 2308-2317. [CrossRef]

6. Kuroda, H.; Tomita, I.; Endo, T. A novel polyaddition of diols with bifunctional acetylenes having electron-withdrawing groups. Macromolecules 1995, 28, 433-436. [CrossRef]

7. Kuroda, H.; Tomita, I.; Endo, T. A novel polyaddition of bifunctional acetylenes containing electron-withdrawing groups. Iii. Synthesis of polymers having $\beta$-alkoxyenoate moieties by the reaction of internal diynes with diols. J. Polym. Sci. Part A Polym. Chem. 1996, 34, 1597-1604. [CrossRef]

8. Kuroda, H.; Tomita, I.; Endo, T. A novel polyaddition of bifunctional acetylenes containing electron-withdrawing groups: 4. Synthesis of polymers having enone moieties by the reaction of ynones with bifunctional heteronucleophiles. Polymer 1997, 38, 3655-3662. [CrossRef]

9. Shi, Y.; Bai, T.; Bai, W.; Wang, Z.; Chen, M.; Yao, B.; Sun, J.Z.; Qin, A.; Ling, J.; Tang, B.Z. Phenol-yne click polymerization: An efficient technique to facilely access regio- and stereoregular poly(vinylene ether ketone)s. Chem.-Eur. J. 2017, 23, 10725-10731. [CrossRef]

10. Zeng, X. Recent advances in catalytic sequential reactions involving hydroelement addition to carbon-carbon multiple bonds. Chem. Rev. 2013, 113, 6864-6900. [CrossRef]

11. Oonishi, Y.; Gomez-Suarez, A.; Martin, A.R.; Nolan, S.P. Hydrophenoxylation of alkynes by cooperative gold catalysis. Angew. Chem. Int. Ed. Engl. 2013, 52, 9767-9771. [CrossRef]

12. Wang, J.; Bai, T.; Chen, Y.; Ye, C.; Han, T.; Qin, A.; Ling, J.; Tang, B.Z. Palladium/Benzoic acid-catalyzed regio- and stereoselective polymerization of internal diynes and diols through $\mathrm{C}\left(\mathrm{sp}^{3}\right)-\mathrm{H}$ activation. ACS Macro Lett. 2019, 8, 1068-1074. [CrossRef]

13. Zhang, J.; Sun, J.Z.; Qin, A.; Tang, B.Z. Transition-metal-free polymerization of bromoalkynes and phenols. Macromolecules 2019, 52, 2949-2955. [CrossRef]

14. Si, H.; Wang, K.; Song, B.; Qin, A.; Tang, B.Z. Organobase-catalysed hydroxyl-yne click polymerization. Polym. Chem. 2020, 11, 2568-2575. [CrossRef]

15. Schwesinger, R.; Hasenfratz, C.; Schlemper, H.; Walz, L.; Peters, E.-M.; Peters, K.; von Schnering, H.G. How strong and how hindered can uncharged phosphazene bases be? Angew. Chem. Int. Ed. Engl. 1993, 32, 1361-1363. [CrossRef]

16. Schwesinger, R.; Schlemper, H. Peralkylated polyaminophosphazenes-extremely strong, neutral nitrogen bases. Angew. Chem. Int. Ed. Engl. 1987, 26, 1167-1169. [CrossRef]

17. Kondo, Y. Superbases for Organic Synthesis: Guanidines, Amidines and Phosphazenes and Related Organocatalysts, 1st ed.; Ishikawa, T., Ed.; John Wiley \& Sons, Ltd.: Hoboken, NJ, USA, 2009; Volume 5, p. 145.

18. Wang, J.; Li, B.; Xin, D.; Hu, R.; Zhao, Z.; Qin, A.; Tang, B.Z. Superbase catalyzed regio-selective polyhydroalkoxylation of alkynes: A facile route towards functional poly(vinyl ether)s. Polym. Chem. 2017, 8, 2713-2722. [CrossRef]

19. Takahashi, S.; Cohen, L.A.; Miller, H.K.; Peake, E.G. Calculation of the pka values of alcohols from .Sigma. Constants and from the carbonyl frequencies of their esters. J. Org. Chem 1971, 36, 1205-1209. [CrossRef]

20. Kresge, A.J.; Pruszynski, P.; Stang, P.J.; Williamson, B.L. Base-catalyzed hydrogen exchange and estimates of the acid strength of benzoyl- and (trimethylsilyl)acetylene in aqueous solution. A correlation between acetylene pka estimates and hydroxide ion catalytic coefficients for hydrogen exchange. J. Org. Chem 1991, 56, 4808-4811. [CrossRef]

21. Kuroda, H.; Tomita, I.; Endo, T. A novel polyaddition of bifunctional acetylenes containing electron-withdrawing groups. 2. Synthesis of polymers having .Beta.-alkylmercaptoenoate moieties by the reaction with dithiols. Macromolecules 1995, 28, 6020-6025. [CrossRef] 
22. Jim, C.K.W.; Qin, A.; Lam, J.W.Y.; Mahtab, F.; Yu, Y.; Tang, B.Z. Metal-free alkyne polyhydrothiolation: Synthesis of functional poly(vinylenesulfide)s with high stereoregularity by regioselective thioclick polymerization. Adv. Funct. Mater. 2010, 20, 1319-1328. [CrossRef]

23. Truong, V.X.; Dove, A.P. Organocatalytic, regioselective nucleophilic "click" addition of thiols to propiolic acid esters for polymer-polymer coupling. Angew. Chem. Int. Ed. 2013, 52, 4132-4136. [CrossRef] [PubMed]

24. Bell, C.A.; Yu, J.; Barker, I.A.; Truong, V.X.; Cao, Z.; Dobrinyin, A.V.; Becker, M.L.; Dove, A.P. Independent control of elastomer properties through stereocontrolled synthesis. Angew. Chem. Int. Ed. 2016, 55, 13076-13080. [CrossRef] [PubMed]

25. Liu, Y.; Wang, J.; Huang, D.; Zhang, J.; Guo, S.; Hu, R.; Zhao, Z.; Qin, A.; Tang, B.Z. Synthesis of 1,5-regioregular polytriazoles by efficient nme4oh-mediated azide-alkyne click polymerization. Polym. Chem. 2015, 6, 5545-5549. [CrossRef]

26. Li, B.; Liu, Y.; Nie, H.; Qin, A.; Tang, B.Z. Phosphazene base-mediated azide-alkyne click polymerization toward 1,5-regioregular polytriazoles. Macromolecules 2019, 52, 4713-4720. [CrossRef]

27. Hu, R.; Li, W.; Tang, B.Z. Recent advances in alkyne-based multicomponent polymerizations. Macromol. Chem. Phys. 2016, 217, 213-224. [CrossRef]

28. Wei, B.; Li, W.; Zhao, Z.; Qin, A.; Hu, R.; Tang, B.Z. Metal-free multicomponent tandem polymerizations of alkynes, amines, and formaldehyde toward structure- and sequence-controlled luminescent polyheterocycles. J. Am. Chem. Soc. 2017, 139, 5075-5084. [CrossRef]

29. Huang, Y.; Chen, P.; Wei, B.; Hu, R.; Tang, B.Z. Aggregation-induced emission-active hyperbranched poly(tetrahydropyrimidine) s synthesized from multicomponent tandem polymerization. Chin. J. Polym. Sci. 2019, 37, 428-436. [CrossRef]

30. Hu, Y.; Han, T.; Yan, N.; Liu, J.; Liu, X.; Wang, W.-X.; Lam, J.W.Y.; Tang, B.Z. Visualization of biogenic amines and in vivo ratiometric mapping of intestinal ph by aie-active polyheterocycles synthesized by metal-free multicomponent polymerizations. Adv. Funct. Mater. 2019, 29, 1902240. [CrossRef]

31. Zhang, Y.; Tseng, N.-W.; Deng, H.; Kwok, R.T.K.; Lam, J.W.Y.; Tang, B.Z. Bcl3-mediated polycoupling of alkynes and aldehydes: A facile, metal-free multicomponent polymerization route to construct stereoregular functional polymers. Polym. Chem. 2016, 7, 4667-4674. [CrossRef]

32. Han, T.; Zhang, Y.; He, B.; Lam, J.W.Y.; Tang, B.Z. Functional poly(dihalopentadiene)s: Stereoselective synthesis, aggregationenhanced emission and sensitive detection of explosives. Polymers 2018, 10, 821. [CrossRef] [PubMed]

33. Fu, W.; Dong, L.; Shi, J.; Tong, B.; Cai, Z.; Zhi, J.; Dong, Y. Synthesis of polyquinolines via one-pot polymerization of alkyne, aldehyde, and aniline under metal-free catalysis and their properties. Macromolecules 2018, 51, 3254-3263. [CrossRef]

34. Dong, L.; Lan, T.; Liang, Y.; Guo, S.; Zhang, H. Metal-free [2+2+1] cycloaddition polymerization of alkynes, nitriles, and oxygen atoms to functional polyoxazoles. RSC Adv. 2020, 10, 24368-24373. [CrossRef]

35. Huang, D.; Liu, Y.; Qin, A.; Tang, B.Z. Recent advances in alkyne-based click polymerizations. Polym. Chem. 2018, 9, 2853-2867. [CrossRef]

36. Li, B.; Huang, D.; Qin, A.; Tang, B.Z. Progress on catalytic systems used in click polymerization. Macromol. Rapid Commun. 2018, 39, 1800098. [CrossRef] [PubMed]

37. Qin, A.; Tang, L.; Lam, J.W.Y.; Jim, C.K.W.; Yu, Y.; Zhao, H.; Sun, J.; Tang, B.Z. Metal-free click polymerization: Synthesis and photonic properties of poly(aroyltriazole)s. Adv. Funct. Mater. 2009, 19, 1891-1900. [CrossRef]

38. Wei, Q.; Deng, H.; Cai, Y.; Lam, J.W.Y.; Li, J.; Sun, J.; Gao, M.; Qin, A.; Tang, B.Z. Efficient polymerization of azide and active internal alkynes. Macromol. Rapid Commun. 2012, 33, 1356-1361. [CrossRef]

39. Li, H.; Mei, J.; Wang, J.; Zhang, S.; Zhao, Q.; Wei, Q.; Qin, A.; Sun, J.; Tang, B.Z. Facile synthesis of poly(aroxycarbonyltriazole)s with aggregation-induced emission characteristics by metal-free click polymerization. Sci. China Chem. 2011, 54, 611-616. [CrossRef]

40. Li, H.; Wang, J.; Sun, J.Z.; Hu, R.; Qin, A.; Tang, B.Z. Metal-free click polymerization of propiolates and azides: Facile synthesis of functional poly(aroxycarbonyltriazole)s. Polym. Chem. 2012, 3, 1075-1083. [CrossRef]

41. Li, H.; Wu, H.; Zhao, E.; Li, J.; Sun, J.Z.; Qin, A.; Tang, B.Z. Hyperbranched poly(aroxycarbonyltriazole)s: Metal-free click polymerization, light refraction, aggregation-induced emission, explosive detection, and fluorescent patterning. Macromolecules 2013, 46, 3907-3914. [CrossRef]

42. Li, H.; Li, L.; Wu, H.; Lam, J.W.Y.; Sun, J.Z.; Qin, A.; Tang, B.Z. Ferrocene-based poly(aroxycarbonyltriazole)s: Synthesis by metal-free click polymerization and use as precursors to magnetic ceramics. Polym. Chem. 2013, 4, 5537-5541. [CrossRef]

43. Li, H.; Wang, Z.; Li, J.; Zhao, E.; Sun, J.Z.; Lam, J.W.Y.; Qin, A.; Tang, B.Z. Facile preparation of light refractive poly(aroxycarbonyltriazole)s by metal-free click polymerization. Macromol. Chem. Phys. 2014, 215, 1036-1041. [CrossRef]

44. Wang, X.; Hu, R.; Zhao, Z.; Qin, A.; Tang, B.Z. Self-healing hyperbranched polytriazoles prepared by metal-free click polymerization of propiolate and azide monomers. Sci. China Chem. 2016, 59, 1554-1560. [CrossRef]

45. Lang, M.-N.; Chi, W.-W.; Han, T.; Zhao, Q.-Z.; Li, H.-K.; Tang, B.Z.; Li, Y.-F. Synthesis of functional hyperbranched poly (methyltriazolylcarboxylate)s by catalyst-free click polymerization of butynoates and azides. Chin. J. Polym. Sci. 2020, 38, 1171-1177. [CrossRef]

46. Wang, Q.; Li, H.; Wei, Q.; Sun, J.Z.; Wang, J.; Zhang, X.A.; Qin, A.; Tang, B.Z. Metal-free click polymerizations of activated azide and alkynes. Polym. Chem. 2013, 4, 1396-1401. [CrossRef] 
47. Wang, Q.; Chen, M.; Yao, B.; Wang, J.; Mei, J.; Sun, J.Z.; Qin, A.; Tang, B.Z. A polytriazole synthesized by 1,3-dipolar polycycloaddition showing aggregation-enhanced emission and utility in explosive detection. Macromol. Rapid Commun. 2013, 34, 796-802. [CrossRef]

48. Wu, Y.; He, B.; Quan, C.; Zheng, C.; Deng, H.; Hu, R.; Zhao, Z.; Huang, F.; Qin, A.; Tang, B.Z. Metal-free poly-cycloaddition of activated azide and alkynes toward multifunctional polytriazoles: Aggregation-induced emission, explosive detection, fluorescent patterning, and light refraction. Macromol. Rapid Commun. 2017, 38, 1700070. [CrossRef]

49. Wu, Y.; He, B.; Wang, J.; Hu, R.; Zhao, Z.; Huang, F.; Qin, A.; Tang, B.Z. Efficient and regioselectivity-tunable metal-free polycycloaddition of activated azide and alkynes. Macromol. Rapid Commun. 2017, 38, 1600620. [CrossRef]

50. Pathigoolla, A.; Gonnade, R.G.; Sureshan, K.M. Topochemical click reaction: Spontaneous self-stitching of a monosaccharide to linear oligomers through lattice-controlled azide-alkyne cycloaddition. Angew. Chem. Int. Ed. 2012, 51, 4362-4366. [CrossRef]

51. Pathigoolla, A.; Sureshan, K.M. A crystal-to-crystal synthesis of triazolyl-linked polysaccharide. Angew. Chem. Int. Ed. 2013, 52, 8671-8675. [CrossRef]

52. Pathigoolla, A.; Sureshan, K.M. Synthesis of triazole-linked homonucleoside polymers through topochemical azide-alkyne cycloaddition. Angew. Chem. Int. Ed. 2014, 53, 9522-9525. [CrossRef] [PubMed]

53. Krishnan, B.P.; Rai, R.; Asokan, A.; Sureshan, K.M. Crystal-to-crystal synthesis of triazole-linked pseudo-proteins via topochemical azide-alkyne cycloaddition reaction. J. Am. Chem. Soc. 2016, 138, 14824-14827. [CrossRef] [PubMed]

54. Krishnan, B.P.; Sureshan, K.M. Topochemical azide-alkyne cycloaddition reaction in gels: Size-tunable synthesis of triazole-linked polypeptides. J. Am. Chem. Soc. 2017, 139, 1584-1589. [CrossRef] [PubMed]

55. Konkolewicz, D.; Gray-Weale, A.; Perrier, S. Hyperbranched polymers by thiol-yne chemistry: From small molecules to functional polymers. J. Am. Chem. Soc. 2009, 131, 18075-18077. [CrossRef] [PubMed]

56. Konkolewicz, D.; Gaillard, S.; West, A.G.; Cheng, Y.Y.; Gray-Weale, A.; Schmidt, T.W.; Nolan, S.P.; Perrier, S. Luminescent hyperbranched polymers: Combining thiol-yne chemistry with gold-mediated $\mathrm{c}-\mathrm{h}$ bond activation. Organometallics 2011, 30, 1315-1318. [CrossRef]

57. Barbey, R.; Perrier, S. A facile route to functional hyperbranched polymers by combining reversible addition-fragmentation chain transfer polymerization, thiol-yne chemistry, and postpolymerization modification strategies. ACS Macro Lett. 2013, 2, 366-370. [CrossRef]

58. Konkolewicz, D.; Poon, C.K.; Gray-Weale, A.; Perrier, S. Hyperbranched alternating block copolymers using thiol-yne chemistry: Materials with tuneable properties. Chem. Commun. 2011, 47, 239-241. [CrossRef] [PubMed]

59. Liu, W.; Dong, C.-M. Versatile strategy for the synthesis of hyperbranched poly( $\varepsilon$-caprolactone)s and polypseudorotaxanes thereof. Macromolecules 2010, 43, 8447-8455. [CrossRef]

60. Cai, T.; Li, M.; Zhang, B.; Neoh, K.-G.; Kang, E.-T. Hyperbranched polycaprolactone-click-poly(n-vinylcaprolactam) amphiphilic copolymers and their applications as temperature-responsive membranes. J. Mater. Chem. B 2014, 2, 814-825. [CrossRef]

61. Cook, A.B.; Barbey, R.; Burns, J.A.; Perrier, S. Hyperbranched polymers with high degrees of branching and low dispersity values: Pushing the limits of thiol-yne chemistry. Macromolecules 2016, 49, 1296-1304. [CrossRef]

62. Han, J.; Zhao, B.; Gao, Y.; Tang, A.; Gao, C. Sequential click synthesis of hyperbranched polymersvia the $\mathrm{A}_{2}+\mathrm{CB}_{2}$ approach Polym. Chem. 2011, 2, 2175-2178. [CrossRef]

63. Han, J.; Zheng, Y.; Zhao, B.; Li, S.; Zhang, Y.; Gao, C. Sequentially hetero-functional, topological polymers by step-growth thiol-yne approach. Sci. Rep. 2014, 4, 4387. [CrossRef] [PubMed]

64. Pötzsch, R.; Komber, H.; Stahl, B.C.; Hawker, C.J.; Voit, B.I. Radical thiol-yne chemistry on diphenylacetylene: Selective and quantitative addition enabling the synthesis of hyperbranched poly(vinyl sulfide)s. Macromol. Rapid Commun. 2013, 34, 1772-1778. [CrossRef] [PubMed]

65. Pötzsch, R.; Stahl, B.C.; Komber, H.; Hawker, C.J.; Voit, B.I. High refractive index polyvinylsulfide materials prepared by selective radical mono-addition thiol-yne chemistry. Polym. Chem. 2014, 5, 2911-2921. [CrossRef]

66. Wei, Q.; Pötzsch, R.; Komber, H.; Pospiech, D.; Voit, B. High refractive index hyperbranched polymers with different naphthalene contents prepared through thiol-yne click reaction using di-substituted asymmetric bulky alkynes. Polymer 2014, 55, 5600-5607. [CrossRef]

67. Wei, Q.; Zan, X.; Qiu, X.; Öktem, G.; Sahre, K.; Kiriy, A.; Voit, B. High refractive index hyperbranched polymers prepared by two naphthalene-bearing monomers via thiol-yne reaction. Macromol. Chem. Phys. 2016, 217, 1977-1984. [CrossRef]

68. Gazzo, S.; Manfredi, G.; Pötzsch, R.; Wei, Q.; Alloisio, M.; Voit, B.; Comoretto, D. High refractive index hyperbranched polyvinylsulfides for planar one-dimensional all-polymer photonic crystals. J. Polym. Sci. Part B Polym. Phys. 2016, 54, 73-80. [CrossRef]

69. Yao, B.; Mei, J.; Li, J.; Wang, J.; Wu, H.; Sun, J.Z.; Qin, A.; Tang, B.Z. Catalyst-free thiol-yne click polymerization: A powerful and facile tool for preparation of functional poly(vinylene sulfide)s. Macromolecules 2014, 47, 1325-1333. [CrossRef]

70. Yao, B.; Hu, T.; Zhang, H.; Li, J.; Sun, J.Z.; Qin, A.; Tang, B.Z. Multi-functional hyperbranched poly(vinylene sulfide)s constructed via spontaneous thiol-yne click polymerization. Macromolecules 2015, 48, 7782-7791. [CrossRef]

71. Alameddine, B.; Baig, N.; Shetty, S.; Al-Mousawi, S.; Al-Sagheer, F. Triptycene-containing poly(vinylene sulfone) derivatives from a metal-free thiol-yne click polymerization followed by a mild oxidation reaction. Polymer 2018, 154, 233-240. [CrossRef]

72. Du, J.; Huang, D.; Li, H.; Qin, A.; Tang, B.Z.; Li, Y. Catalyst-free click polymerization of thiol and activated internal alkynes: A facile strategy toward functional poly( $\beta$-thioacrylate)s. Macromolecules 2020, 53, 4932-4941. [CrossRef] 
73. He, B.; Su, H.; Bai, T.; Wu, Y.; Li, S.; Gao, M.; Hu, R.; Zhao, Z.; Qin, A.; Ling, J.; et al. Spontaneous amino-yne click polymerization: A powerful tool toward regio- and stereospecific poly( $\beta$-aminoacrylate)s. J. Am. Chem. Soc. 2017, 139, 5437-5443. [CrossRef]

74. He, B.; Zhen, S.; Wu, Y.; Hu, R.; Zhao, Z.; Qin, A.; Tang, B.Z. Cu(I)-Catalyzed amino-yne click polymerization. Polym. Chem. 2016, 7, 7375-7382. [CrossRef]

75. He, B.; Zhang, J.; Zhang, H.; Liu, Z.; Zou, H.; Hu, R.; Qin, A.; Kwok, R.T.K.; Lam, J.W.Y.; Tang, B.Z. Catalyst-free multicomponent tandem polymerizations of alkyne and amines toward nontraditional intrinsic luminescent poly(aminomaleimide)s. Macromolecules 2020, 53, 3756-3764. [CrossRef]

76. Chen, X.; Hu, R.; Qi, C.; Fu, X.; Wang, J.; He, B.; Huang, D.; Qin, A.; Tang, B.Z. Ethynylsulfone-based spontaneous amino-yne click polymerization: A facile tool toward regio- and stereoregular dynamic polymers. Macromolecules 2019, 52, 4526-4533. [CrossRef]

77. Chen, X.; Bai, T.; Hu, R.; Song, B.; Lu, L.; Ling, J.; Qin, A.; Tang, B.Z. Aroylacetylene-based amino-yne click polymerization toward nitrogen-containing polymers. Macromolecules 2020, 53, 2516-2525. [CrossRef]

78. Hu, R.; Chen, X.; Zhou, T.; Si, H.; He, B.; Kwok, R.T.K.; Qin, A.; Tang, B.Z. Lab-in-cell based on spontaneous amino-yne click polymerization. Sci. China Chem. 2019, 62, 1198-1203. [CrossRef]

79. Li, W.; Wu, X.; Zhao, Z.; Qin, A.; Hu, R.; Tang, B.Z. Catalyst-free, atom-economic, multicomponent polymerizations of aromatic diynes, elemental sulfur, and aliphatic diamines toward luminescent polythioamides. Macromolecules 2015, 48, 7747-7754. [CrossRef] 